\title{
Relationship of simple reaction time and aerobic and anaerobic capacities with performance of recreational adult orienteers
}

\section{Relacão do tempo de reação simples e das capacidades aeróbica e anaeróbica com o desempenho de adultos recreacionais em Orientação}

\author{
Carolina Cunha Kuhl \\ (1) https://orcid.org/0000-0002-4849-0964 \\ Thiago Emannuel Medeiros 2 \\ (1) https://orcid.org/0000-0003-2745-9762 \\ Mayara Maciel Batista ${ }^{3}$ \\ (D) https://orcid.org/0000-0002-6542-941X \\ Paulo Henrique Pauli ${ }^{3}$ \\ (iD) https://orcid org/0000-0001-7975-5526 \\ Marcos Vinícius Soares Martins \\ (D) https://orcid.org/0000-0001-8930-9466 \\ Marcos Roberto Queiroga ${ }^{4}$ \\ (D) https://orcid.org/0000-0002-9284-976X \\ Marcus Peikriszwili Tartaruga \\ (D) https://orcid.org/0000-0003-1173-2816
}

Abstract - This st $\dot{\mathbf{V}} \dot{\mathbf{V}}$ imed to examine the effects of Simple Reaction Time (SRT), Maximal Oxygen Uptake ( $\mathbf{V} \mathbf{V}_{\mathrm{O}_{2} \max }$ ) and Maximal Anaerobic Power (Pmax) on the performance of category A recreational adult orienteers of both sexes. Sixteen subjects ( 8 men and 8 women; age: $30 \pm 4$ and $2 \overrightarrow{\mathbf{V}} \dot{\mathbf{V}}$ years; body mass $78.8 \pm 5.9$ and $69.2 \pm 10.4 \mathrm{~kg}$; SRT: $1.391 \pm 0.19$ and

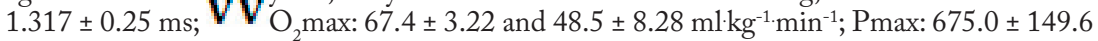
and $458.4 \pm 88.62 \mathrm{~W}$ ), were submitted to thre ${ }_{\mathbf{V}}$ luation sessions: sample characterization

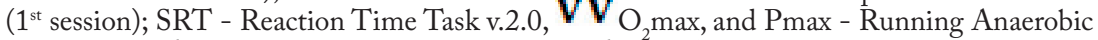
Sprint Test ( $2^{\text {nd }}$ session); official Orienteering test ( $3^{\text {rd }}$ session). Results of comparison (Student's T-test) and relation (Pearson Product-Moment Correlation and Multiple Linear Regression) tests showed significant relationships between independent variables and performance. $\mathrm{Pr}_{\dot{\mathbf{V}}}$

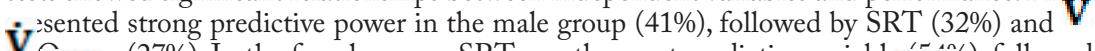

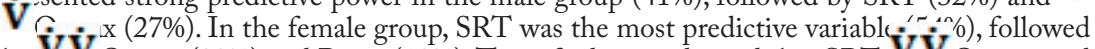

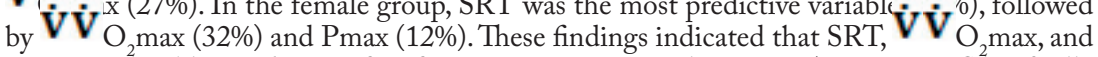
Pmax are variables predictive of performance in recreational category A orienteers. Specifically in recreational orienteers with high cardiorespiratory capacities, Pmax seems to be the main predictor variable. Conversely, SRT becomes the variable with the greatest predictive power.

Key words: Oxygen uptake; Metabolism; Reaction time.

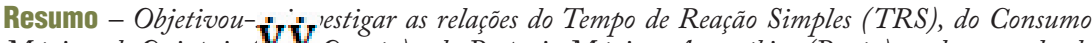

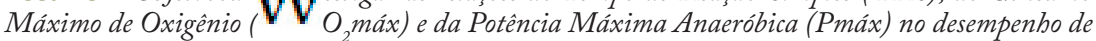
homens e mulheres, adultos da categoria A, praticantes recreacionais de Orientação. Dezesseis sujeitos (8 homens e 8 mulheres; idade: $3 C_{\dot{\mathbf{V}}} \dot{\mathbf{V}} 27 \pm 5$ anos; mass a corporal 78, 8 $\pm 5,9$ e 69,2 $\pm 10,4 \mathrm{~kg}$; TRS:

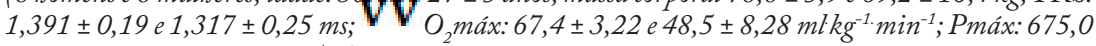

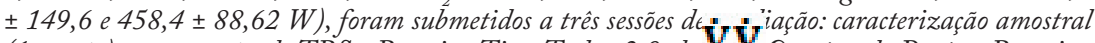
(1 $1^{a}$ sessão); mensuraçôes do TRS - Reaction Time Task v.2.0, do V V ${ }_{O_{2}}$ máx e da Pmáx - Running Anaerobic Sprint Test (2a sessão); prova de Orientação ( $3^{a}$ sessão). Os resultados de comparaçãa (teste $T$ de Students) e de relação (Correlação Linear Produto-Momento de Pearson e Regressão Linear Múltipla) demonstraram relações estatisticamente significativas entre as variáveis independentes e 0 desempenho ' náx apresentou forte poder de predição no grupo masculino (41\%), seguida do TRS

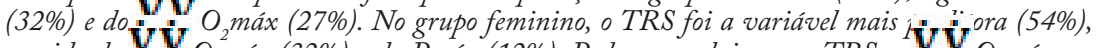
seguida do $\mathbf{V} \mathbf{V}_{\mathrm{O}_{2} \text { máx }(32 \%) \text { e da Pmáx (12\%). Pode-se concluir que o TRS, o }} \mathbf{V} \mathbf{V}_{\mathrm{O}_{2} \text { máx e a }}$ Pmáx são variáveis preditoras do desempenho em adultos praticantes recreacionais de Orientação da categoria A. Especificamente, em sujeitos com maiores capacidades cardiorrespiratórias, a Pmáx parece ser a principal variável preditora. Em contrapartida, o TRS passa a ser a variável com maior poder de predição.

Palavras-chave: Consumo de oxigênio; Metabolismo; Tempo de reação.
1 State University of Mid-Western Paraná. Laboratory of Biomechanics and Energetics of the Human Movement. Guarapuava, PR. Brazil

2 University of the State of Santa Catarina. Laboratory of Gender, Education, Sexuality and Corporeity. Florianópolis, SC. Brazil

3 Federal University of Paraná. Graduate Program in Physical Education. Curitiba, PR. Brazil

4 State University of Mid-Western Paraná. Laboratory of Experimental Physiology Applied to Physical Activity. Guarapuava, PR. Brazil

Received: 25 February 2018 Accepted: 09 May 2019

How to cite this article Kuhl CC, Medeiros TE, Batista MM, Pauli PH, Martins MVS, Queiroga MR, Tartaruga MP. Relationship of simple reaction time and aerobic and anaerobic capacities with performance of recreational adult orienteers. Rev Bras Cineantropom Desempenho Hum 2019, 21:e55492. D0l: http://dx.doi. org/10.1590/1980-0037.2019v21e55492

Copyright: This work is licensed under a Creative Commons Attribution 4.0 International License. 


\section{INTRODUCTION}

Motor learning is characterized by changes in the ability to perform a given task based on experience and practice, usually systematized, influencing performance improvement. These changes occur in number, complexity and quality of execution, being of mechanical-organic or intentionality origin ${ }^{1}$. According to Guzman et al. $^{2}$, learning success depends on many factors, mainly the development of motor skills considered as stable and / or lasting individual traits from inherited or acquired abilities.

Among the various motor capacities already identified, the Simple Response Time (SRT) - defined as the time interval from the visual, auditory or tactile stimulus to the beginning of a response is highlighted. According to Shanks et al. ${ }^{3}$, SRT represents the level of neuromuscular coordination in which stimuli are decoded by the body through different physicochemical and mechanical processes, propagating through afferent pathways until they reach the brain as sensory stimuli. Sequentially, the motor response is transmitted by efferent neurons that penetrate the medulla through the dorsal or sensory root by performing synapses and leading information to the desired motor unit ${ }^{3}$. In sports, especially in modalities whose performance is strongly influenced by cognitive aspects, for example, in Orienteering, SRT has been widely investigated ${ }^{4}$.

Orientation Sport, known as orienteering, consists of an endurance modality that involves physical and mental components aiming to travel a certain distance guided by a compass in the shortest possible time in varied and unknown terrain, passing through control points (CPs) indicated on a map made according to the rules of the International Orienteering Federation (IOF). Described as a cross-country type event, Orienteering differs from other sports modalities due to the influence of physiological ${ }^{5}$ and cognitive ${ }^{2}$ parameters on performance.

Chalopin ${ }^{6}$ evaluated adult male orienteering athletes and verified average Maximum Oxygen Uptake ( $\dot{\mathbf{V}}_{\mathrm{O}_{2} \max }$ ) values corresponding to $71.7 \pm$ $5.7 \mathrm{ml} \cdot \mathrm{kg}^{-1} \cdot \mathrm{min}^{-1}$, similar to values found by Moser et al. ${ }^{7}$ and Gjerset et al. ${ }^{8}$.

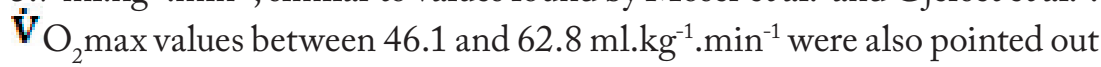
in a review study published by Creagh and Reilly ${ }^{5}$ as being determinant for good performance in Orienteering.

A possible justification for the importance of maximum cardiorespiratory capacity in performance in endurance tests, such as Orienteering, may be related to the Anaerobic Threshold (AT). Tartaruga et al. ${ }^{9}$ investigated

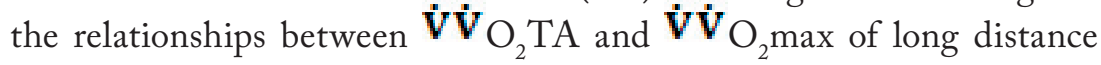
runners according to body mass (traditional method), by the allometric exponent characteristic of the investigated group $(b=0.69)$ and by lean mass, and found strong correlations in all forms of expression $(r=0.64,0.54$ and 0.60 , respectively). Creagh and Reilly ${ }^{5}$ analyzed adult Orienteering

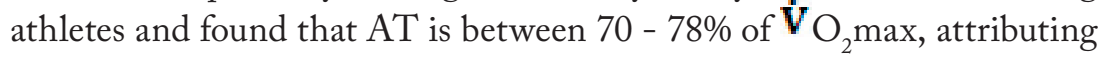
the improvement in maximum cardiorespiratory capacity to the increase

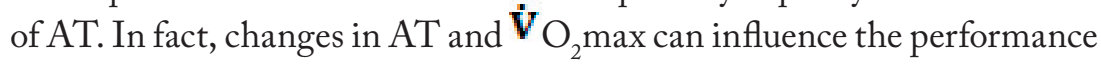


of recreational exercises ${ }^{9}$.

The effect of exercise intensity on mental function during Orienteering has also been investigated and is represented by an inverted U-shaped curve corresponding to the relationship between physiological intensity and number of correct responses. Hintermann and Hintermann ${ }^{10}$ have suggested that at high exercise intensities, mental tasks can be compromised as a result of the onset of mental fatigue. High blood ammonia concentrations released by the muscle during exercise can be one of the mechanisms responsible for mental fatigue, compromising performance, for example, in Orienteering ${ }^{11}$.

Despite the importance of maximum cardiorespiratory capacity, anaerobic parameters have also been decisive on specific occasions during Orienteering events. Dresel ${ }^{12}$ investigated the high lactate concentrations during an Orienteering event and demonstrated the importance of anaerobic capacity in performance. Values between 4.4 and $6.7 \mathrm{mmol} / \mathrm{L}$, with peak values close to $7.3 \mathrm{mmol} / \mathrm{L}$, were observed in the first moments of Orienteering events. In addition, high maximum anaerobic power (Pmax) values were also observed, as already verified in other sport modalities ${ }^{5}$. Pmax corresponds to the highest amount of energy released per unit of time by a system. Anaerobic capacity is the total amount of energy available from this system.

Although there are studies highlighting the importance of SRT ${ }^{2}$ and cardiorespiratory capacities ${ }^{5}$ in Orienteering, interactions of these parameters with performance in category $\mathrm{A}$ adult practitioners of recreational exercises have been little investigated. In addition, it is known that other factors, such as sports experience can also influence performance in the modality ${ }^{2}$. Understanding and inducing performance-influencing variables through specific periodizations means respecting physiological and cognitive limits in order to obtain better results. Therefore, the aim of the present study was to investigate the relationships of SRT, $\dot{\mathbf{V}}_{\mathrm{O}_{2}} \max$ and Pmax in the performance of category $\mathrm{A}$ adult recreational orienteers of both sexes.

\section{METHOD}

Sixteen recreational adult orienteers, 8 men and 8 women, with sports experience of at least 2 years and 6 events / year in category A - registered in the Orienteering Federation of Paraná (FPO) and in the Brazilian Confederation of Orienteering (FBO) - free from injuries and medical and / or pharmacological treatments, voluntarily participated in the present study. The minimum sample number required for the study ( $\mathrm{n}=14,7$ males and 7 females) was determined considering the publications of Moser et al. ${ }^{7}$ and Gjerset et al. ${ }^{8}$, using the Computer Programs for Epidemiologic Analyses-PEPI software, with 0.05 significance level and $80 \%$ power. All subjects were instructed not to consume caffeine or any type of stimulant 3 -h prior to evaluation sessions, as well as to avoid intense physical activity for the last $24 \mathrm{~h}$. 


\section{Experimental Procedures}

Subjects were submitted to three evaluation sessions corresponding to the sample characterization ( $1^{\text {st }}$ session), specific tests to determine the magnitudes of independent variables ( $2^{\text {nd }}$ session) and an official Orienteering event ( $3^{\text {rd }}$ session), as demonstrated in the experimental design (see figure 1). The first two sessions, with the exception of the Pmax test, were performed in a laboratory specialized in biomechanical and energy analyses of human movement, with controlled temperature $\left(25^{\circ} \mathrm{C}\right)$ and relative humidity (52\%) according to international standards (ISO -85731). The third session corresponded to an Orienteering event recognized by FPO held in the Midwestern region of Paraná / BR. The present study was approved by the Ethics Research Committee of the State University of Mid-Western Paraná - UNICENTRO (3.185.736).
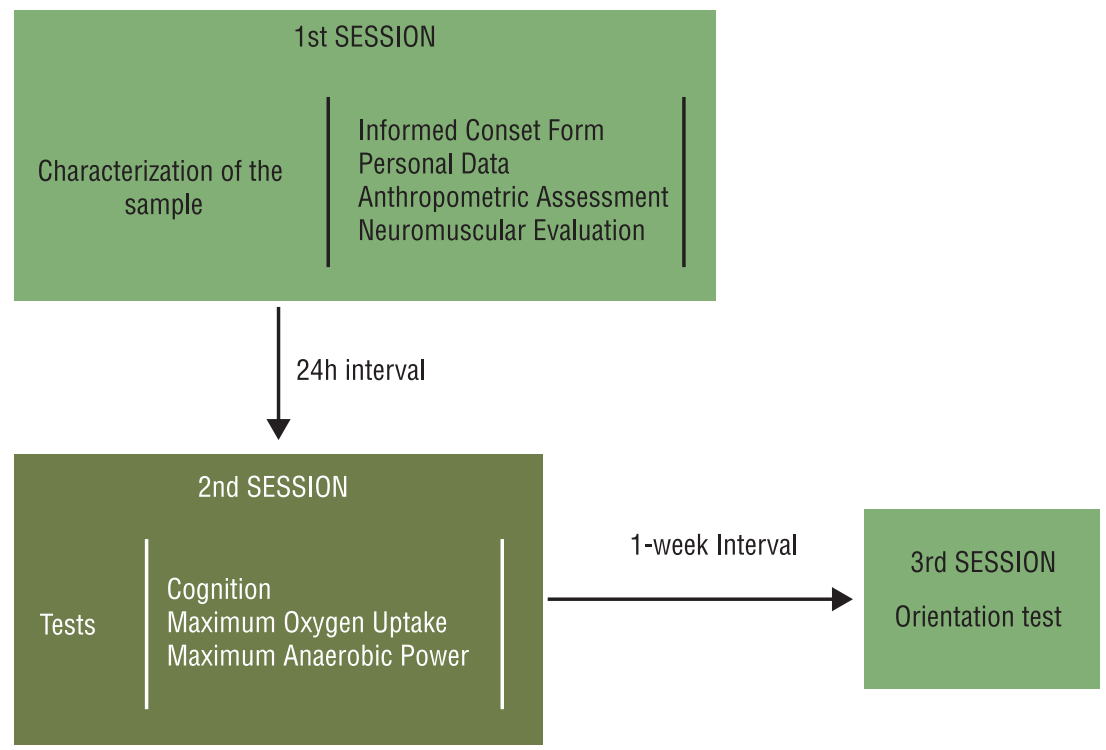

Figure 1. Experimental design

\section{$1^{\text {st }}$ Session - Sampling Characterization}

The Sampling Characterization session consisted of the signing of the Informed Consent Form, completion of document containing personal data and measurements of anthropometric variables (body mass, height and skinfolds) and neuromuscular variables (maximum power of lower limbs, PmaxLL, and maximum height, hmax, determined in the Squat Jump - SJ and Counter Movement Jump - CMJ) tests.

The measurement instruments used in the anthropometric evaluation were: a) Filizola scale (model 31, São Paulo, Brazil), with resolutions of $100 \mathrm{~g}$ and $1 \mathrm{~mm}$, respectively, with capacity of $150 \mathrm{~kg}$; b) 1-meter Starrett tape measure (model S12, São Paulo, Brazil) with $0.1 \mathrm{~mm}$ resolution; c) skinfold caliper (model C-130, Cambridge, USA), with resolution of 0.1 $\mathrm{mm}$. Cefise uniaxial force platform (model SV, São Paulo, Brazil), with capacity of $800 \mathrm{kgf}(8,000 \mathrm{~N})$ and resolution below $0.5 \mathrm{kgf}(5 \mathrm{~N})$ was used 
for PmaxLL and hmax measurements.

After a brief neuromuscular warm-up (4 to 6 vertical jumps), subjects performed three bare maximum jumps in each experimental situation (SJ and $\mathrm{CMJ}$ ), with a 2-min interval with maximum values in each situation analyzed.

\section{$2^{\text {nd }}$ session - Tests}

SRT has been a tool adopted by psychologists and health professionals to investigate underlying behavioral processes, including the biological and cognitive principles of learning and memory. Consequently, several computer programs have been developed, among them, the Reaction Time Task v.2.0 - developed by Okazaki ${ }^{13}$ and adopted in the present study. It is used to analyze paradigms related to cognition, allowing manipulating the execution time of the test and the type of stimuli with the aim of quantifying the number of responses and SRT. In the present study, subjects were submitted to a 5-min test in a quiet, isolated and noise-free place, according to procedures adopted by Shanks and Cameron ${ }^{3}$. Seated in front of a computer and using a mouse, visual stimuli (numbers and colors) were used to quantify the number of correct answers and SRT (mean value).

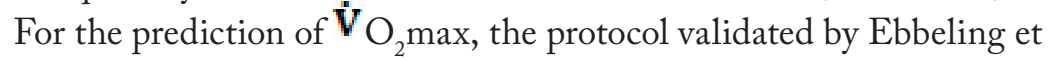
al. ${ }^{14}$ was used, with determination power corresponding to $92 \%$ (estimated

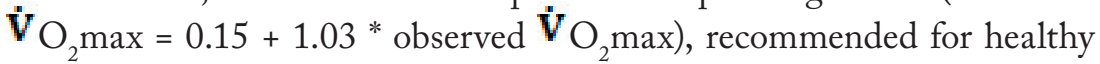
non-athlete adults aged 20-59 years. The protocol consists in initially estimating maximum heart rate (HRmax) of each subject by adopting the equation: $208-0.7 *$ age. After 5-min at rest, heart rate is measured (HRrest) and a 4-min warm-up is started on a treadmill. In the present study, MOVEMENT treadmill (model RT350, São Paulo, Brazil) was adopted. After warm-up, the speed was set for HR between 50\% and 70\% determined according to the following equations.

After 4 minutes ( $1^{\text {st }}$ stage), treadmill inclination was raised to $5 \%$, and the subject must remain at the same speed ( $2^{\text {nd }}$ stage). The two mean HR of the last 30 seconds corresponding to the third and fourth minutes are recorded. If there is variation greater than $5 \mathrm{bpm}$, a further 1 minute of test is added with a new record. HR to be considered in the $\dot{\mathbf{V}} \dot{\mathbf{V}}_{\mathrm{O}_{2} \max }$ estimation (equation c) corresponds to the average of the last two records.

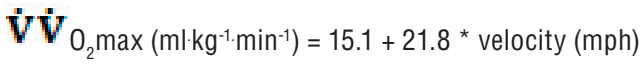

$$
\begin{aligned}
& -0.327{ }^{*} \mathrm{HR}(\mathrm{bpm}) \\
& -0.263 \text { * velocity * age (years) } \\
& +0.00504{ }^{*} \mathrm{HR}{ }^{*} \text { age }+5.98 \text { * } \operatorname{sex}(0 \text { female; } 1 \text { male })
\end{aligned}
$$

Finally, Pmax and fatigue index (FI) were measured by adopting the Running Anaerobic Sprint Test (RAST). It is a field test developed at the 
University of Wolverhampton and validated by Zagatto et al. ${ }^{15}$ with the aim of determining the minimum (Pmin), average (Pmed) and maximum power $\left(\mathrm{Pmax}_{\mathrm{ABS}}\right)$, all absolute $(\mathrm{ABS})$ and relative (REL), corresponding to the anaerobic capacity, in addition to the level of neuromuscular fatigue. The test corresponds to 6 maximum $35-\mathrm{m}$ runs with intervals of $10-\mathrm{s}$. Through variables body mass, distance and time of displacement, Pmax (absolute or relative) and FI can be estimated according to the following equations. According to Zagatto et al. ${ }^{15}$, RAST shows significant correlations with the Wingate test (Pmax $r=0.46$ and FI $r=0.63)$.

$\operatorname{Pmax}_{\text {ABS }}(\mathrm{W})=\left[\right.$ Body mass $\left.(\mathrm{kg}){ }^{*} \operatorname{Distance}^{2}(\mathrm{~m})\right] /$ time $^{3}(\mathrm{~s})$

$\operatorname{Pmax}_{\text {PEL }}\left(\mathrm{W} \cdot \mathrm{kg}^{-1}\right)=\mathrm{Pmax}_{\text {maS }} /$ Body mass

IF $(\%)=[(P \max -P \min ) \star 100] / P \max$

The mentioned protocol was carried out in a multi-sport university gymnasium, and the running time in each of the six situations was measured through a system composed of two CEFISE (Speed Test 6.0, Nova Odessa, Brazil) photocells located at the ends of the course.

\section{$3^{\text {rd }}$ Session - Orienteering test}

The third and last session, aimed at measuring performance, consisted of an Orienteering event recognized by FPO. All subjects, classified as adult $\mathrm{A}$, according to rules of the Brazilian Orienteering Confederation (CBO), covered a minimum distance of $3.8 \mathrm{~km}$ for women and $4.6 \mathrm{~km}$ for men, with final performances corresponding to averages of test times of each subject of both groups. In this case, the shorter the test time, the higher the performance. The control and verification system adopted was ENTRAINEMENT SPORTident (16020, Locunolé, France). The test took place between 9 am and 11am, on a sunny day, with average temperature of $28^{\circ} \mathrm{C}$.

\section{Statistical Procedures}

Shapiro-Wilk tests were performed to verify data normality, Student's T for independent samples and Pearson's Linear Product-Moment Correlation. Finally, Multiple Linear Regression analysis - Enter method was performed. The significance level adopted in all the tests was 0.05 using the statistical package Statistical for Social Sciences Software - SPSS, version 20.0.

\section{RESULTS}

Despite similarities in age and body fat percentage, men and women presented statistically significant differences in variables body mass, height, hmax and $P \max _{L L}$, the latter being also different intra-group (see table 1). Male performance was higher, as was the average participation in official events (11 vs. 8 events / year) demonstrating a probable higher sporting experience of these subjects. 
Table 1. Mean values and standard deviations of variables age, body mass, height, body fat, height (hmax) and maximal power of lower limbs (PmaxLL) in Squat Jump (SJ) and Counter Movement Jump (CMJ) and test time of recreational adult (level A) orienteers.

\begin{tabular}{lcc}
\hline Variables & Men $(n=8)$ & Women $(n=8)$ \\
\hline Age (years) & $30 \pm 4$ & $27 \pm 5$ \\
Body Mass $(\mathrm{kg})$ & $78.8 \pm 5.9$ & $69.2 \pm 10.4^{*}$ \\
Height $(\mathrm{m})$ & $1.79 \pm 0.07$ & $1.61 \pm 0.08^{*}$ \\
Body Fat (\%) & $24.5 \pm 1.4$ & $22.9 \pm 3.8$ \\
hmax SJ & $31.4 \pm 4.4$ & $25.3 \pm 5.3^{\star}$ \\
hmax CMJ & $36.7 \pm 5.1^{\#}$ & $29.7 \pm 4.7^{\star \#}$ \\
Pmax $_{\text {MI }}$ SJ & $16.7 \pm 2.7$ & $13.5 \pm 2.8^{*}$ \\
Pmax $_{\text {MI }}$ CMJ & $21.2 \pm 2.3^{\#}$ & $18.1 \pm 2.8^{\star \#}$ \\
Test time (h:min:s) $^{*}$ & $0: 53: 53 \pm 0: 13: 12$ & $1: 10: 29 \pm 0: 18: 55^{*}$ \\
\hline
\end{tabular}

Note: Statistically significant inter-group $\left(^{*}\right)$ and intra-group (\#) differences resulting from the application of the t-Students tests for independent and dependent variables, respectively.

The mean $\dot{\mathbf{V}}_{\mathrm{O}_{2} \text { max and absolute }}\left(\operatorname{Pmax}_{\mathrm{ABS}}\right)$ and relative $\mathrm{Pmax}\left(\mathrm{Pmax}^{-}\right.$ ${ }_{\mathrm{REL}}$ ) values also showed statistically significant differences between men and women, indicating greater cardiorespiratory capacity of male subjects. However, SRT, number of cognitive hits and FI - commonly determined in intermittent high-intensity tests but associated with aerobic metabolism - did not present statistically significant inter-group differences. Mean values and standard deviations of independent variables corresponding to the $2^{\text {nd }}$ evaluation session are shown in table 2 .

Table 2. Average values and standard dev ${ }_{\dot{V}}$ is of variables simple reaction time (SRT), number of cognitive hits, maximum oxygen uptake $\left(\mathbf{V} \mathbf{V}_{\mathrm{O}_{2}}\right.$ max), anaerobic power (absolute values - $\mathrm{Pmax}_{\mathrm{ABS}}$ and relative values - $\operatorname{Pmax}_{\mathrm{REL}}$ ) and fatigue index (FI) of recreational adult (level A) orienteers.

\begin{tabular}{lcc}
\hline Variables & Men $(n=8)$ & Women $(n=8)$ \\
\hline SRT $(\mathrm{ms})$ & $1.391 \pm 0.19$ & $1.317 \pm 0.25$ \\
Cognitive hits $(n)$ & $53 \pm 6$ & $53 \pm 10$ \\
$\dot{\mathbf{V}} \dot{V}_{\mathrm{O}_{2} \max \left(\mathrm{ml} \mathrm{kg}^{-1} \cdot \mathrm{min}^{-1}\right)}$ & $67.4 \pm 3.22$ & $48.5 \pm 8.28^{*}$ \\
$\operatorname{Pmax}_{\text {ABS }}(\mathrm{W})$ & $675.0 \pm 149.6$ & $458.4 \pm 88.62^{*}$ \\
$\operatorname{Pmax}_{\text {REL }}\left(\mathrm{W} \cdot \mathrm{kg}^{-1}\right)$ & $8.7 \pm 1.93$ & $6.6 \pm 1.27^{*}$ \\
$\mathrm{FI}(\%)$ & $39.0 \pm 8.41$ & $36.1 \pm 8.82$ \\
\hline
\end{tabular}

Note: statistically significant inter-group differences $\left({ }^{*}\right)$ resulting from the application of the t-Students test for independent variables.

Strong and significant correlations (men: $r=0.89$ and women: $r=$ 0.97 ) between SRT and number of cognitive hits were also verified in both groups, demonstrating that the higher the SRT, the greater the number of cognitive hits and, consequently, better choices on the routes to be covered.

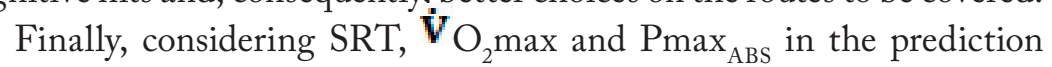
model, strong associations (men: 63.6\% and women: $89.5 \%$ ) with performance were observed. In the male group, $\operatorname{Pmax}_{\mathrm{ABS}}$ presented greater prediction capacity (b) of performance, followed by SRT and $\dot{\mathbf{V}}_{\mathrm{O}_{2} \text { max. }}$ In the female group, SRT had higher propensity, followed by $\dot{\mathbf{V}}_{\mathrm{O}_{2}} \max$ and $\operatorname{Pmax}_{\mathrm{ABS}}$ (see table 3). 


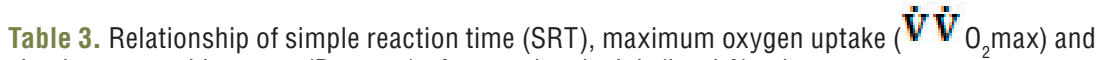
absolute anaerobic power $\left(\mathrm{Pmax}_{\mathrm{ABS}}\right)$ of recreational adult (level $\left.\mathrm{A}\right)$ orienteers.

\begin{tabular}{lcccccccc}
\hline \multirow{2}{*}{ Variables } & \multicolumn{4}{c}{ Men $(n=8)$} & \multicolumn{5}{c}{ Women $(n=8)$} \\
\cline { 2 - 9 } & $r$ & $\alpha$ & $b(\%)$ & order & $r$ & $\Downarrow$ & $b(\%)$ & order \\
\hline SRT (ms) & -0.78 & 0.014 & 32 & 2 & -0.85 & 0.014 & 54 & 1 \\
$\dot{\mathbf{V}} \dot{\mathbf{V}}_{\mathrm{O}_{2} \max \left(\mathrm{ml} \mathrm{kg}^{-1} \cdot \mathrm{min}^{-1}\right)}$ & -0.78 & 0.012 & 27 & 3 & -0.88 & 0.009 & 32 & 2 \\
$\operatorname{Pmax}_{\mathrm{ABS}}(\mathrm{W})$ & -0.69 & 0.043 & 41 & 1 & -0.91 & 0.004 & 12 & 3 \\
\hline
\end{tabular}

Note: correlation coefficient $(r)$; significance index $(\alpha)$, regression index $(b)$; order of dependent variable prediction (order). Results of Pearson's Product-Moment Correlation and Multiple Linear Regression Analysis.

\section{DISCUSSION}

The aim of the present study was to investigate the associations of SRT, $\dot{\mathbf{V}}_{\mathrm{O}_{2}} \max$ and Pmax in the performance of category A recreational adult orienteers of both genders. As main result, it was verified that the larger the magnitudes of independent variables adopted in the present study, the shorter the test time - consequently, the higher the performance. Pmax and SRT were the parameters that presented greater capacity to predict performances in the male and female groups, respectively.

According to Cureton et al. $^{16}$, sex is one of the main determinants of performance in several sports due to morphological and physiological differences between sexes. Aerobic capacity is an example, where female $\dot{\mathbf{V}}_{\mathrm{O}_{2} \max }$ values, corresponding to $70-75 \%$ of males, have been verified ${ }^{17}$. According to the Brazilian Society of Sports Medicine, although muscle fiber compositions are similar between men and women, Pmax tends to be higher in men due to higher cellular volumes, regardless of muscle fiber type. Although the adaptability to training is similar for men and women, larger cellular volumes give men greater cardiorespiratory and neuromuscular capacities, making sports performance of these subiects higher (6 to 15\%) to that of women ${ }^{17}$.

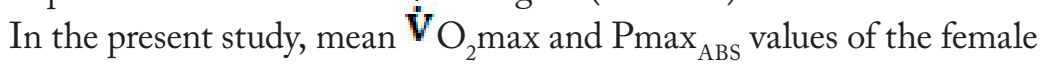
group corresponded to $72 \%$ and $68 \%$, respectively, of the male group - corroborating findings previously described. In addition, the average number of participations in events / year was also higher in the male group. Consequent$1 y$, sex and the probable greater sport experience can justify the better average performance verified in the men, being 23\% higher compared to women.

Variables hmax and $\mathrm{Pmax}_{\mathrm{LL}}$, measured in SJ and CMJ tests, also presented higher values in the male group. Many studies have investigated the different neuromuscular responses resulting from vertical jumps of men and women ${ }^{18}$. Although several studies have demonstrated higher hmax and $\operatorname{Pmax}_{\mathrm{LL}}$ values due to the high rates of concentric and eccentric force production in men compared to women, some recent results have been contradictory ${ }^{19}$. Although differences in neuromuscular parameters are greatly attenuated when comparisons between sexes are conducted according to body mass values, plasma concentrations of the major anabolic hormones (testosterone, GH and IGF-1) at rest or after intense exercise, 
quite different between men and women, can justify these differences ${ }^{20}$. In addition, changes in the proportion of muscle fiber types may also interfere with the power production capacity, consequently, in the behavior of neuromuscular parameters, since women tend to present less difference in the proportion between type I and type II fibers when compared with men ${ }^{21}$.

Regarding performance in SJ and CMJ, strength parameters determinants of the power of lower limbs, have been investigated. Pulo et al. ${ }^{22}$ point out that in CMJ, there is an eccentric movement of agonist muscles, followed by a concentric movement in which the jump result is attributed in large part to the use of elastic energy produced in the stretch-shortening cycle (CAE) and tendinous stiffness in velocity generation. Specifically in SJ, there is only the concentric phase, and performance is primarily attributed to the neural recruitment capacity. As a result of such characteristics, in which strength and velocity are requested differently in SJ and CMJ, there are differences in hmax and $\operatorname{Pmax}_{\mathrm{LL}}$ in the order of \pm 15 and $\pm 23 \%$, respectively ${ }^{22}$, justifying the findings of the present study.

FI has an inverse relationship with performance at high intensities and is directly related to cardiovascular problems ${ }^{23}$. According to Marque et al. ${ }^{24}$, changes in FI are related to possible aerobic adaptations, such as changes in oxidative capacity due to changes in circulating blood volume and changes in enzymatic and mitochondrial levels, influencing performance in high-intensity intermittent activities. However, although it is a variable predictive of fatigue in anaerobic tests, determined in high-intensity intermittent protocols, FI seems to be more associated with aerobic parameters ${ }^{25}$. In the present study, the male group presented significantly higher $\dot{\mathbf{V}} \dot{\mathbf{V}}_{\mathrm{O}_{2}}$ max and Pmax values compared to the female group. However, FI of both groups was similar, suggesting that aerobic parameters such as AT ( $\Delta \%$ of $\dot{\mathbf{V}} \dot{\mathbf{V}}_{\mathrm{O}_{2} \text { max }}$ ) and movement economy were similar between groups. Likewise, SRT and number of cognitive hits were also similar between men and women, demonstrating that the level of neuromuscular coordination is similar among recreational adult orienteers, very different when compared with professionals or competitors of other sports ${ }^{2}$.

Although some predictive performance parameters in Orienteering do not present statistically significant intra-group differences, the present study demonstrates the existence of strong associations of SRT, $\dot{\mathbf{V}} \dot{\mathbf{V}}_{\mathrm{O}_{2}}$ max and Pmax with sports performance in both groups investigated. According to results, Pmax was the variable most predictive of performance (41\%) in the male group, composed of more aerobically conditioned and homogeneous subjects. The female group presented SRT (54\%) as the parameter with the highest performance prediction. According to Hébert-Losier ${ }^{26}$, subjects with high cardiorespiratory capacity, mainly Pmax, tend to perform better in Orienteering events due to the better use of the stretch-shortening cycle and the rapid production of maximum strength, especially of lower limbs. Moradi and Esmaeilzadeh ${ }^{27}$ point out that factors such as age, caffeine and / or drug intake, diseases, lifestyle and practice of physical activity can influence SRT. In addition to these factors, recent studies have shown that 
body mass, especially obesity in young people, adults and the elderly can affect some cognitive parameters such as $\mathrm{SRT}^{28}$, which may be neuromechanically understood ${ }^{28}$. According to Skurvydas et al. ${ }^{29}$, the higher the body mass, especially of sedentary people whose cardiorespiratory capacity is not so determinant of sports performance, the greater the rigidity in kinematic chains, thus, the greater the SRT.

Moser et al. ${ }^{7}$ investigated some physiological determinants of performance in Orienteering and verified the importance of AT. According to the authors, the AT is quickly reached, with effort remaining at high levels, suggesting an excessive energy expenditure with great anaerobic participation - something verified in the various changes in average speed from one point to the other (between 50 and $285 \mathrm{~m} \cdot \mathrm{min}^{-1}$ ) in the course of Orienteering events. That is, Orienteering is a sport modality that requires great aerobic resistance, with significant influence of Pmax - variables that determine sports performance, especially when experienced practitioners are analyzed.

On the other hand, Kolb et al..$^{30}$ investigated the influence of several Orienteering performance predictors and found that cognitive parameters can explain by approximately $46 \%$ the variability of results found among orienteers, which effect is strongly related to the ability to interpret the map - something in constant development with practice. Although SRT did not present statistically significant differences between men and women, in the present study, there was a strong prediction of performance by this variable, especially in the female group, corroborating the results found by Kolb et al. ${ }^{30}$. In groups composed of subjects with low cardiorespiratory capacity, SRT seems to become the variable with great capacity to predict the performance of recreational category A orienteers.

\section{CONCLUSION}

The present study allows concluding that SRT, $\dot{\mathbf{V}} \dot{\mathbf{V}}_{\mathrm{O}_{2} \max \text { and Pmax are }}$ variables predictive of performance of category A adult recreational orientees of both sexes. Specifically in subjects with greater cardiorespiratory capacity, Pmax seems to be the main predictor variable in this modality. In contrast, SRT becomes the variable with the greatest predictive capacity. As practical application, the present study contributed with relevant information in the scope of training for better prediction and sports performance.

\section{Acknowledgments}

The authors would like to thank the Paraná Orienteering Federation (FPO) and the Lobo-Bravo Orienteering Club (COLB).

\section{COMPLIANCE WITH ETHICAL STANDARDS}

\section{Funding}

This research did not receive any specific grant from funding agencies in the public, commercial, or non-profit sectors. This study was funded by the authors. 


\section{Ethical approval}

Ethical approval was obtained from the local Human Research Ethics

Committee of Midwest State University - UNICENTRO (3.185.736).

\section{Conflict of interest statement}

The authors have no conflict of interests to declare.

\section{Author Contributions}

Conceptualization, C.C.K., T.E.M., M.M.B., P.H.P., M.V.S.M., M.R.Q. and M.P.T.; Methodology, C.C.K., M.M.B., P.H.P., M.V.S.M. and M.P.T.; Data analysis, C.C.K., T.E.M., M.M.B., P.H.P., M.V.S.M. and M.P.T.; Writing-original draft, C.C.K., T.E.M., M.M.B., P.H.P., M.V.S.M., M.R.Q. and M.P.T.; Writing-review and editing, C.C.K. and M.P.T.

\section{REFERENCES}

1. Frank C, Land WM, Schack T. Perceptual-Cognitive Changes During Motor Learning: The Influence of Mental and Physical Practice on Mental Representation, Gaze Behavior, and Performance of a Complex Action. Front Psychol 2015;6:1981.

2. Guzman JF, Pablos AM, Pablos C. Perceptual-cognitive skills and performance in orienteering. Percept Mot Skills 2008;107(1):159-164.

3. Shanks DR, Cameron A. The effect of mental practice on performance in a sequential reaction time task. J Mot Behav 2000;32(3):305-313.

4. Chamberlin CJ, Magill RA. Preparation and control of rapid, multisegmented responses in simple and choice environments. Res QExerc Sport 1989;60(3):256-267.

5. Creagh U, Reilly T. Physiological and biomechanical aspects of orienteering. Sports Med 1997;24(6):409-418.

6. Chalopin C. Physical and Psychological characteristics of French orienteers. Sci. J. Orienteering 1994;10(1-2):58-62.

7. Moser T, Gjerset A, Johansen E, Vadder L. Aerobic and anaerobic demands in orienteering. Sci J Orienteering 1995;11(1):3-30.

8. Gjerset A, Johansen E, Moser T. Aerobic and anaerobic demands in short distance orienteering. Sci J Orienteering 1997;13(1-2):4-25.

9. Tartaruga MP, Beilke DD, Coertjens M, Baptista RR, Tartaruga LAP, Kruel LFM. Relation between submaximum and maximum oxygen uptake of elite distance runners and elite rowers. Rev Educ Física/UEM 2008;141(2):22-33.

10. Hintermann B, Hintermann M. Injuries in orienteering: a study of the 1991 Swiss 6-days orienteering event. Sci J Orienteering 1992;8(2):72-78.

11. Mutch BJ, Banister EW. Ammonia metabolism in exercise and fatigue: a review. Med Sci Sports Exerc 1983;15(1):41-50.

12. Dresel U. Lactate acidosis with different stages in the course of a competitive orienteering performance. Sci J Orienteering 1985;1:4-13.

13. Candido CRC, Faquin BS, Okazaki VHA. Analysis of the constrained action hypothesis and the effect of the focus of attention in balance on unstable platform. Rev Educ Fis/UEM 2012;23(4):655-662.

14. Ebbeling CB, Ward A, Puleo EM, Widrick J, Rippe JM. Development of a singlestage submaximal treadmill walking test. Med Sci Sports Exerc 1991;23(8):966-973.

15. Zagatto AM, Beck WR, Gobatto CA. Validity of the running anaerobic sprint test for assessing anaerobic power and predicting short-distance performances. J Strength Cond Res 2009;23(6):1820-1827. 
16. Cureton K, Bishop P, Hutchinson P, Newland H, Vickery S, Zwiren L. Sex difference in maximal oxygen uptake. Effect of equating hemoglobin concentration. Eur J Appl Physiol Occup Physiol 1986;54(6):656-660.

17. Sparling PB. A meta-analysis of studies comparing maximal oxygen uptake in men and women. Res QExerc Sport 1980;51(3):542-552.

18. McMahon JJ, Rej SJE, Comfort P. Sex differences in Countermovement Jump phase characteristics. Sports 2017;5(8):1-11.

19. Rice PE, Goodman CL, Capps CR, Triplett NT, Erickson TM, McBride JM. Force- and power-time curve comparison during jumping between strengthmatched male and female basketball players. Eur J Sport Sci 2017;17(3):286-293.

20. Borst SE, De Hoyos DV, Garzarella L, Vincent K, Pollock BH, Lowenthal DT, et al. Effects of resistance training on insulin-like growth factor-I and IGF binding proteins. Med Sci Sports Exerc 2001;33:648-653.

21. Hostler D, Schwirian CI, Campos G, Toma K, Crill MT, Hagerman GR, et al. Skeletal muscle adaptations in elastic resistance-trained young men and women. Eur J Appl Physiol 2001;86:112-118.

22. Pupo JD, Detanico D, Santos SGd. Kinetic parameters as determinants of vertical jump performance. Rev Bras Cienc Mov 2012;14(1):41-51.

23. Sharma VK, Subramanian SK, Arunachalam V. Evaluation of body composition and its association with cardiorespiratory fitness in south Indian adolescents. Indian J Physiol Pharmacol 2013;57(4):399-405.

24. Marques RF, Costa HA, Júnior JdaHA, Marques KRM, Brune R, Júnior MNSdeO. Influência do VO2máx no índice de fadiga de jogadores de futebol e futsal universitários. Rev Bras Futebol Futsal 2012;4(13):224-228.

25. De Oliveira SFM, De Oliveira LMFT, Brito-Gomes JL, Melo RJP, Costa MdaC, Guimarães FJdeSP. Comparison of two anaerobic indirect tests in professional soccer players and their correlations with aerobic performance. Rev Bras Ciênc Esporte 2017;39(3):307-313.

26. Hébert-Losier K1, Jensen K, Holmberg HC. Jumping and hopping in elite and amateur orienteering athletes and correlations to sprinting and running. Int J Sports Physiol Perform 2014;9(6):993-999.

27. Moradi A, Esmaeilzadeh. Simple reaction time and obesity in children: whether there is a relationship? Environ Health Prev Med 2017;14;22(1):1-6.

28. Kamijo K, Pontifex MB, Khan NA, Raine LB, Scudder MR, Drollette ES, et al. The negative association of childhood obesity to cognitive control of action monitoring. Cere Cortex 2014;24:654-662.

29. Skurvydas A, Gutnik B, Zuoza AK, Nash D, Zuoziene IJ, Mickeviciene D. Relationship between simple reaction time and body mass index. Homo 2009;60(1):77-85.

30. Kolb H, Sobotka R, Werner R. A model of performance-determining components in orienteering. Sci J Orienteering 1987;3(1):71-81.

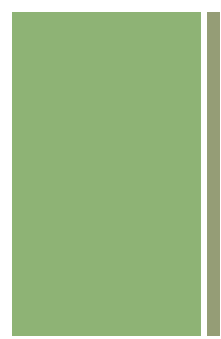

Corresponding author

Marcus Peikriszwili Tartaruga,

Universidade Estadual do Centro-Oeste (UNICENTRO)

Setor de Ciências da Saúde (SES/G)

Departamento de Educação Física Bacharelado (DEDUF/G)

Grupo de Pesquisa em Mecânica e Energética do Movimento Humano (MEMH)

Alameda Élio Antonio Dalla Vecchia, 838

Vila Carli, Guarapuava-PR, Brasil

CEP: $85040-167$

Email: mtartaruga@hotmail.com 